\title{
Epifluorescence microscope methods for bacterial enumeration in a 4-chlorophenol degrading consortium
}

\author{
C.C. Pacheco, C.C. Alves, L. Barreiros, P.M.L. Castro* \& P.C.M. Teixeira \\ Escola Superior de Biotecnologia, Universidade Católica Portuguesa, Rua Dr. António Bernardino de Almeida, \\ 4200-072 Porto, Portugal \\ *Author for correspondence (Fax: +351 22 5090351; E-mail:plc@esb.ucp.pt)
}

Key words: degrading consortia, fluorescence dyes, starvation, ultramicrocells, viable but non-culturable bacteria

\begin{abstract}
Epifluorescence microscope methods, namely BacLight, direct epifluorescence filter technique and Rhodamine 123, consistently underestimated plate bacterial counts in a 4-chlorophenol degrading consortium. Cells capable of passing through $0.2 \mu \mathrm{m}$ filters, referred as 'ultramicrocells', were found. Although cell counts were higher when traditional methods were used, BacLight and direct epifluorescence filter technique were convenient techniques for the systematic monitoring of bacteria involved in biodegradation processes, as results were consistent and available within a short time.
\end{abstract}

\section{Introduction}

Chlorinated organic compounds form one of the most important groups of xenobiotics that enter the environment. Microorganisms play a major role in the breakdown of such pollutants. In biological treatment systems, microbial viability/activity assessment is required (Ziglio et al. 2002). Enumeration of active microorganisms during biodegradation processes usually relies on conventional culture-dependent methods, which are time-consuming and may underestimate the total number of viable/active bacteria, due to the presence of cells in the viable but non-culturable physiological state (Fiksdal \& Tryland 1999). This is quite common when cells are exposed to some kind of stressing conditions (Kaprelyants \& Kell 1992). Survival under starvation conditions may be an important factor for biotreatment operations, as shut-off periods are common in the industrial environment. Determining the viability and activity of the microorganisms under these periods is crucial for the evaluation of the robustness of the treatment system (Carvalho et al. 2001). Several methods for the determination of total cell biomass and the active cell biomass have been introduced in environmental microbiology (Vollertsen et al. 2001). DNA staining and evaluation of cellular functions are the two main approaches. Direct microscopy has long been established as a rapid method for bacterial enumeration. Fluorochrome stains have become increasingly used because most microorganisms present in natural environments cannot be enumerated accurately by traditional plate counts (Bartscht et al. 1999).

The objective of this study was to compare rapid microbial viability assessment methods with the conventional plating methodology, for the enumeration of bacteria present in a 4-chlorophenol degrading consortium. The effects of long starvation periods in the viability of the degrading consortium were also evaluated.

\section{Materials and methods}

\section{Cultivation and starvation conditions}

A 4-chlorophenol - (4-CP) - degrading consortium, obtained in earlier studies (Carvalho et al. 2001) and composed of at least three morphologically different bacterial strains, identified by the API system as 
Burkholderia cepacia (ID probability 95.7\%), Sphingobacterium multivorum (ID probability $99.9 \%$ ), and one organism identified with low descrimination between Chryseomonas luteola, Burkholderia cepacia or Sphingomonas paucimobilis, was cultivated in minimal salts medium supplemented with $50 \mathrm{mg} \mathrm{4-CP}{ }^{-1}$, hereafter referred as minimal medium, as the sole source of carbon and energy. Cultures were incubated aerobically at $25^{\circ} \mathrm{C}$ at $100 \mathrm{rpm}$. Growth of the consortium was monitored by measuring the optical density at $600 \mathrm{~nm}$, and by determining chloride release due to the biodegradation of 4-CP (Carvalho et al. 2001). Non-inoculated minimal medium served as a control for non-biological chloride liberation. Starvation of the consortium cells was conducted by incubating the above cells suspensions at $25^{\circ} \mathrm{C}$ at $100 \mathrm{rpm}$, without feeding and sub-culturing.

\section{Conventional methods for bacterial enumeration}

Culturable bacteria present in the samples were enumerated by spread plating of culture samples $(0.1 \mathrm{ml})$ on to nutrient agar (LAB M, Amersham, Bury, UK), R2A (Difco), and minimal medium. Plates were incubated aerobically for $48 \mathrm{~h}$ at $25^{\circ} \mathrm{C}$.

\section{Epifluorescence microscope methods}

BacLight viability test: BacLight viability kit (L7012; Molecular Probes, Eugene, OR) contains two dyes: SYTO 9 and propidium iodide. The DNA-stain SYTO 9 stains all cells but propidium iodide only penetrates cells with damaged cell membranes. In the cell, SYTO 9 is reduced when propidium iodide is present, resulting in propidium iodide staining those bacteria with a damaged cell membrane red. In the present work, viable cells were counted as described by Ramalho et al. (2001).

Rhodamine $123(\mathrm{Rh} 123): 10 \mu \mathrm{l}$ of $\mathrm{Rh} 123$ at $1 \mathrm{mg} \mathrm{ml}^{-1}$, was added to $990 \mu \mathrm{l}$ sample and incubated for $90 \mathrm{~min}$ in the dark. The mixture was filtered through $0.2 \mu \mathrm{m}$ Nucleopore polycarbonate black filters, and observed by epifluorescence microscopy, as described by Ramalho et al. (2001).

5-Cyano-2,3-di-4-tolyl-tetrazolium chloride (CTC) reduction assay: experiments were carried out essentially as described by Ramalho et al. (2001) using a CTC solution at $5 \mathrm{mM}$ and incubating for 90 min. Cells were counted as described by Ramalho et al. (2001). Direct epifluorescence filter technique (DEFT): $1 \mathrm{ml}$ sample was filtered through $0.2 \mu \mathrm{m}$

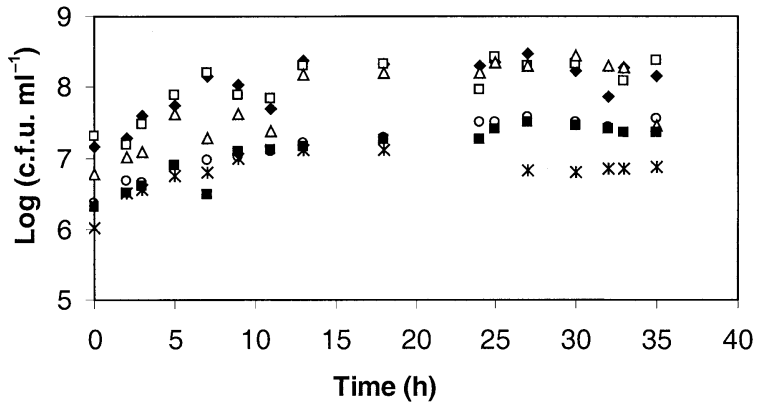

Fig. 1. Growth curves of the consortium using cell counts obtained from plating in nutrient agar $(\diamond)$, R2A $(\square)$, minimal salts medium containing 4-CP $(\triangle)$, and from epifluorescence techniques using BacLight $(\bigcirc)$, Rhodamine 123 (*) and direct epifluorescence filter technique (ם).

Nucleopore polycarbonate black filters (no. 110656) and analysed according to Pettipher et al. (1980).

\section{Bacterial enumeration in the culture filtrate}

A sample of the 4-CP degrading culture was filtered through $0.2 \mu \mathrm{m}$ Nucleopore polycarbonate black filters. The filtrate was plated onto R2A agar $(0.1 \mathrm{ml})$, after serial dilutions in Ringer's solution. Plates were incubated for $48 \mathrm{~h}$ at $25^{\circ} \mathrm{C}$. Samples of the filtrate were also inoculated into nutrient broth and into minimal medium (30\% v/v inocula). Bacterial growth and chloride release were determined. This procedure was repeated twice. Bacteria recovered from the filtrate by $\mathrm{R} 2 \mathrm{~A}$ plating were also re-inoculated into minimal salts medium containing $50 \mathrm{mg} \mathrm{4-CP}{ }^{-1}$, and bacterial growth was assessed.

\section{Results}

\section{Bacterial counts using epifluorescence techniques}

Growth curves were established using nutrient agar, R2A and minimal medium for direct plating, and BacLight, Rh 123 and DEFT staining for epifluorescence detection (Figure 1). The use of CTC was also investigated, however, as the cells were more difficult to visualise with this stain and, moreover, CTC is a more expensive product, there was no further investigation concerning this dye. Bacterial counts (c.f.u. $\mathrm{ml}^{-1}$ ) obtained by direct plating were always about one logarithmic cycle higher than those obtained when the epifluorescence techniques were used. When Rh 123 was used, cell counts were lower, when compared with the other two epifluorescence techniques, an effect 


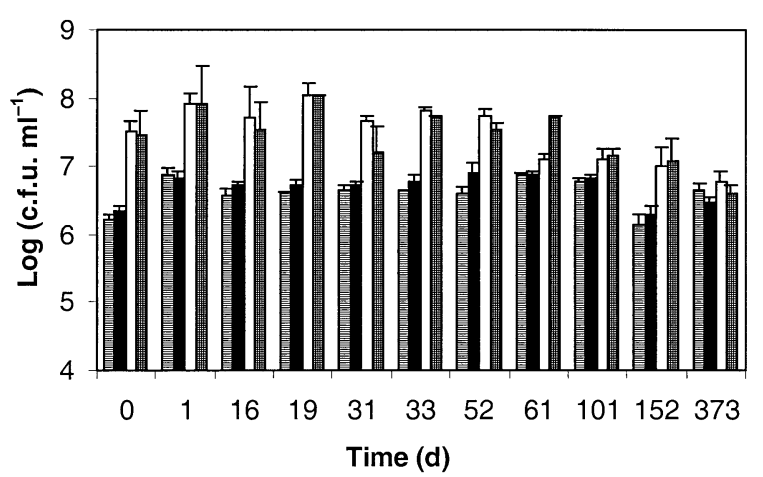

Fig. 2. Monitoring of cell growth/viability during a starvation trial using epifluorescence techniques - BacLight (目) and direct epifluorescence filter technique ( $\square$ ) and conventional cultivation methods - R2A ( $\square$ ) and minimal salts medium containing 4-CP (曲). Data are mean values of two independent replicates \pm standard deviation.

which was noticed later in the culture. Rh 123 may underestimate the number of cells present in a sample, because its uptake depends on the energetic status of the cells, and because this dye does not readily cross the outer membrane, Gram-negative bacteria may not accumulate rhodamine (Kaprelyants et al. 1992). 4-CP did not show any significant interference on bacterial counts obtained using the four epifluorescence techniques (data not shown). The study continued using BacLight and DEFT and the direct plating method.

\section{Bacterial enumeration during a starvation period}

Cell counts of a culture initially grown on minimal medium, were performed over a 373 d starvation period. Cell counts were always higher when direct plate counting was used (Figure 2). These, however, generally decreased with the increase of the starvation period. After the starvation period, the consortium was still able to use 4-CP as single source of carbon, as the chloride concentration found after $48 \mathrm{~h}$ of feeding that culture with $50 \mathrm{mg} \mathrm{4-CP} \mathrm{l}^{-1}$, indicated a stoichiometric chloride release. Non-inoculated minimal medium did not show any chloride liberation for the same time period.

\section{Bacteria in the filtrate}

After several transfers of the degrading consortium with fresh minimal, the culture was aseptically filtered using the same system, and the resulting filtrate was analysed to search for the presence of bacteria. Samples of the filtrate were plated on to R2A agar and cell densities ranging from $3.5 \times 10^{3}-1.2 \times 10^{5}$ c.f.u. $\mathrm{ml}^{-1}$ were found. Addition of filtrate aliquots into nutrient broth and minimal medium led to bacterial growth. Bacteria grown on the R2A plates obtained from the filtrate were re-inoculated in minimal medium as the sole carbon source, and after $4 \mathrm{~d}$, cell growth was observed and, based on chloride release, all the supplied 4-CP was used, indicating that cells passing through the filter were able to degrade 4-CP.

\section{Discussion}

In biodegradation processes, it is important to monitor the viability of bacterial populations that degrade the toxic compounds. Epifluorescence techniques allow us to directly evaluate cellular physiological states, specific metabolic activities, gene expression and total cell densities (McFeters et al. 1995).

The difference observed for bacterial counts when using epifluorescence techniques may be due to a number of reasons. The fluorescence optical counting methods may depend strongly on the type of microorganism and the metabolic states of the cells (Rapposch et al. 2000, Kaprelyants et al. 1992). Moreover, it is usual for cells to aggregate, especially if they are under stressing conditions and are involved in biodegradation processes (Ziglio et al. 2002). Underestimation of bacterial counts by epifluorescent techniques has also been reported in milk (Rapposch et al. 2000). We may also hypothesize that some errors may be inherent to the microscopy and staining techniques.

Ultramicrocells may occur as a result of fragmentation (cell division without growth), typically under starvation conditions (Morita 1985). Ultramicrocells, capable of passing through filters of pore size $0.2 \mu \mathrm{m}$, in natural mineral water, have been reported (Jones et al. 1999). They have also been found for other genera such as Sphingomonas (Eguchi et al. 1996) isolated from aquatic environments. The degrading consortium used in this study comprised Gram-negative rods, including strains of this genera (Carvalho et al. 2001). Further studies, however, pertaining the effect of consortia composition on bacterial counts obtained by EP techniques should be of interest (Rapposch et al. 2000, Kaprelyants et al. 1992), as in biodegradation processes changes in microbial composition over time are common (Carvalho et al. 2001).

The differences observed in this study for plate cell counts and EP techniques could in part be due to the presence of 'ultramicrocells' in the degrading consortium. Starvation may be a relevant factor in 
biotreatment processes, as variations in the concentrations of contaminant in the feed stream is a common scenario (Watanabe et al. 2000). In the present study, the microbial consortium still exhibited 4-CP degradation capacity after over a one-year period of starvation. During that period, the difference between EP counts and direct plate counts became smaller over time, which may indicate that some cells have entered in a VBNC state, due to the starvation induced stress, comparable to what occurs in water (Bartscht et al. 1999). Although cell counts were always higher when traditional methods were used, BacLight and DEFT were shown to be convenient techniques for the systematic monitoring of bacteria present in consortia involved in biodegradation processes, as results were consistent and cells may be counted within a few hours rather than in a few days.

\section{Acknowledgements}

This work was supported by FCT (Fundação para a Ciência e Tecnologia), Portugal (Project PRAXIS/3/3.1/CEG/2575/95). The technical support of Rita Ramalho on the staining techniques is gratefully acknowledged.

\section{References}

Bartscht K, Cypionka H, Overmann J (1999) Evaluation of cell activity and of methods for the cultivation of bacteria from a natural lake community. FEMS Microbiol. Ecol. 28: 249-259.

Carvalho MF, Vasconcelos I, Bull AT, Castro PML (2001) A GAC biofilm reactor for the continuous degradation of 4-chlorophenol: treatment efficiency and microbial analysis. Appl. Microbiol. Biotechnol. 57: 419-426.
Eguchi M, Nishikawa T, MacDonald K, Cavicchioli R, Gottschal JC, Kjelleberg S (1996) Responses to stress and nutrient availability by the marine ultramicrobacterium Sphingomonas sp. strain RB2256. Appl. Environ. Microbiol. 62: 1287-1294.

Fiksdal L, Tryland I (1999) Effect of u.v. light irradiation, starvation and heat on Escherichia coli $\beta$-D-galactosidase activity and other potential viability parameters. J. Appl. Microbiol. 87: 62-71.

Jones CR, Chamberlain AHL, Adams MR (1999) An investigation of the presence of ultramicrocells in natural mineral water. Lett. Appl. Microbiol. 28: 275-279.

Kaprelyants AS, Kell DB (1992) Rapid assessment of bacterial viability and vitality by Rhodamine 123 and flow cytometry. J. Appl. Bact. 72: 410-422.

McFeters G, Yu F, Pyle B, Stewart P (1995) Physiological assessment of bacteria using fluorochromes. J. Microbiol. Meth. 21: $1-13$.

Morita RY (1995) Starvation and miniaturisation of heterotrophs, with special emphasis on maintenance of the starved viable state. In: Fletcher M, Floodgate GD, eds. Bacteria in their Natural Environments. London: Academic Press, pp. 111-130.

Pettipher GL, Mansell R, McKinnon CH, Cousins CM (1980) Rapid membrane filtration-epifluorescence microscopy technique for direct enumeration of bacteria in raw milk. Appl. Environ. Microbiol. 39: 423-429.

Ramalho R, Cunha J, Albano H, Teixeira P, Gibbs P (2001) Improved methods for the enumeration of heterotrophic bacteria in bottled mineral waters. J. Microbiol. Meth. 44: 97-103.

Rapposch S, Zangerl P, Ginzinger W (2000) Influence of fluorescence of bacteria stained with acridine orange on the enumeration of microorganisms in raw milk. J. Dairy Sci. 83: 2753-2758.

Vollertsen J, Jahn A, Nielsen JL, Hvitved-Jacobsen T, Nielsen PH (2001) Comparison of methods for determination of microbial biomass in waste water. Water Res. 35: 1649-1658.

Watanabe K, Miyashita M, Harayama S (2000) Starvation improves survival of bacteria introduced into activated sludge. Appl. Environ. Microbiol. 66: 3905-3910.

Ziglio G, Andreottola G, Barbesti S, Boschetti G, Bruni L, Foladori P, Villa R (2002) Assessment of activated sludge viability with flow cytometry. Water Res. 36: 460-468. 